\title{
PENGARUH MOTIVASI DAN KOMPETENSI TERHADAP KINERJA PEGAWAI NEGERI SIPIL SEKRETARIAT DEWAN PERWAKILAN RAKYAT DAERAH (DPRD) PROPINSI SULAWESI TENGAH
}

\author{
Oleh : \\ Firza Umar Salim \\ (Dosen Fakultas Ekonomi Universitas Alkhairaat)
}

\begin{abstract}
ABSTRAK
Sumber Daya Manusia mempunyai peranan penting dalam setiap kegiatan instansi, walaupun didukung oleh sarana dan prasarana berlebihan tanpa sumber daya yang memiliki motivasi dan kompetensi yang baik maka kegiatan instansi tidak akan berjalan dengan baik. Tujuan penelitian ini adalah untuk mengetahui pengaruh Motivasi dan Kompetensi secara serempak dan parsial terhadap Kinerja Pegawai Negeri Sipil Sekretariat Dewan Perwakilan Rakyat Daerah (DPRD) Propinsi Sulawesi Tengah. Dengan mengambil sampel sebanyak 31 orang dan menggunakan alat statistik Regresi Linear Berganda, maka kesimpulan penelitian ini adalah secara serempak Motivasi dan Kompetensi berpengaruh signifikan terhadap Kinerja Pegawai Negeri Sipil Sekretariat Dewan Perwakilan Rakyat Daerah (DPRD) Propinsi Sulawesi Tengah, demikian pula secara parsial Motivasi dan Kompetensi berpengaruh signifikan terhadap Kinerja Pegawai Negeri Sipil Sekretariat Dewan Perwakilan Rakyat Daerah (DPRD) Propinsi Sulawesi Tengah.
\end{abstract}

Kata Kunci : Motivasi, Kompetensi, dan Kinerja.

\section{LATAR BELAKANG}

Sesungguhnya menjadi Pegawai Negeri Sipil (PNS) yang baik tidaklah mudah, sebab dituntut untuk memiliki kinerja yang baik. Hal ini disebabkan karena PNS adalah abdi negara dan abdi rakyat, yang sudah tentu dituntut untuk dapat memberikan pelayanan optimal kepada rakyat, dan kinerja yang baik. Menurut kaiyeli, kinerja atau performance adalah hasil kerja yang dapat dicapai oleh seseorang atau kelompok orang dalam suatu organisasi, sesuai dengan wewenang dan tanggung jawab masing-masing, dalam rangka mencapai tujuan organisasi bersangkutan secara legal, tidak melanggar hukum dan sesuai dengan moral maupun etika.

Untuk meningkatkan kinerja PNS dalam manajemen yang efektif memerlukan dukungan PNS yang cakap dan kompeten di bidangnya. Di sisi lain pembinaan para PNS termasuk yang harus diutamakan sebagai aset utama instansi pemerintah. Proses belajar harus menjadi budaya instansi pemerintah sehingga keterampilan para PNS dapat dipelihara, bahkan dapat ditingkatkan. Dalam hal ini motivasi PNS dan kompetensinya harus diperhatikan.

Menurut (Rahman, 2019), Dalam organisasi pemerintah maupun swasta pencapaian tujuan ditetapkan melalui sarana dalam bentuk organisasi yang digerakkan oleh sekelompok orang yang berperan aktif sebagai pelaku dalam mencapai tujuan organisasi, pencapaian itu hanya dimungkinkan karena upaya para pegawai yang terdapat pada 
organisasi yang disebut sebagai kinerja pegawai. Pegawai Negeri Sipil yang memiliki sikap perjuangan, pengabdian, disiplin, dan kemampuan profesional sangat mungkin mempunyai kinerja dalam melaksanakan tugas sehingga lebih berdaya guna dan berhasil guna. PNS yang profesional dapat diartikan sebagai sebuah pandangan untuk selalu berpikir, kerja keras, bekerja sepenuh waktu, disiplin, jujur, loyalitas tinggi, dan penuh dedikasi demi untuk keberhasilan pekerjaannya (Hamid, et al., 2003; 40).

Peningkatan sikap, perjuangan, pengabdian, disiplin kerja, dan kemampuan profesional dapat dilakukan melalui serangkaian pembinaan dan tindakan nyata agar upaya peningkatan kinerja PNS dapat menjadi kenyataan. Menurut (Marjun, 2019), Setiap perusahaan harus mampu memberikan pelayanan yang terbaik kepada konsumen, hingga akhirnya tercipta kepuasan dari adanya Dimensi Kualitas Layanan tersebut.

Berdasarkan rumusan di atas, peneliti mencoba untuk mengangkat judul : Pengaruh Motivasi dan Kompetensi Terhadap Kinerja Pegawai Negeri Sipil Sekretariat Dewan Perwakilan Rakyat Daerah (DPRD) Propinsi Sulawesi Tengah.

\section{Permasalahan}

Adapun pokok permasalahan yang di kaji dalam penelitian ini adalah :

1. Apakah Motivasi dan Kompetensi secara serempak berpengaruh terhadap Kinerja Pegawai Negeri Sipil Sekretariat Dewan Perwakilan Rakyat Daerah (DPRD) Propinsi Sulawesi Tengah?

2. Apakah Motivasi berpengaruh terhadap Kinerja Pegawai Negeri
Sipil Sekretariat Dewan Perwakilan Rakyat Daerah (DPRD) Propinsi Sulawesi Tengah?

3. Apakah Kompetensi berpengaruh terhadap Kinerja Pegawai Negeri Sipil Sekretariat Dewan Perwakilan Rakyat Daerah (DPRD) Propinsi Sulawesi Tengah?

4. Variabel apa yang cenderung lebih dominan berpengaruh terhadap Kinerja Pegawai Negeri Sipil Sekretariat Dewan Perwakilan Rakyat Daerah (DPRD) Propinsi Sulawesi Tengah?

\section{Tujuan Penelitian}

Berdasarkan latar belakang masalah dan rumusan masalah, tujuan penelitian ini adalah :

1. Untuk mengetahui dan menganalisis pengaruh Motivasi dan Kompetensi secara serempak terhadap Kinerja;

2. Untuk mengetahui dan menganalisis pengaruh Motivasi terhadap Kinerja Pegawai Negeri Sipil Sekretariat Dewan Perwakilan Rakyat Daerah (DPRD) Propinsi Sulawesi Tengah;

3. Untuk mengetahui dan menganalisis pengaruh Kompetensi terhadap Kinerja Pegawai Negeri Sipil Sekretariat Dewan Perwakilan Rakyat Daerah (DPRD) Propinsi Sulawesi Tengah;

4. Untuk mengetahui dan menganalisis variabel yang cenderung dominan berpengaruh terhadap Kinerja Pegawai Negeri Sipil Sekretariat Dewan Perwakilan Rakyat Daerah (DPRD) Propinsi Sulawesi Tengah.

\section{Kegunaan Penelitian}

Hasil dari penelitian ini di harapkan dapat bermanfaat sebagai berikut :

1. Sebagai bahan informasi dan sekaligus bahan masukan bagi pemerintah Daerah khususnya 
Sekretariat Dewan Perwakilan Rakyat Daerah (DPRD) Propinsi Sulawesi Tengah dalam meningkatkan Kinerja Pegawai Negeri Sipil;

2. Merupakan sumbangan teoritis dan pengembangan ilmu dalam bidang penelitian Sumber Daya Manusia khususnya mengenai Motivasi dan Kompetensi yang mempunyai hubungan dengan Kinerja

\section{METODE PENELITIAN}

Lokasi penelitian ini adalah Sekretariat Dewan Perwakilan Rakyat Daerah (DPRD) Propinsi Sulawesi Tengah, dengan subyeknya adalah Pegawai Negeri Sipil. Pemilihan lokasi penelitian ini didasarkan pada karakteristik pekerjaan Pegawai Negeri Sipil di Sekretariat Dewan Perwakilan Rakyat Daerah (DPRD) Propinsi Sulawesi Tengah, yang cenderung membutuhkan kompetensi yang tidak sama dengan kompetensi Pegawai Negeri Sipil pada umumnya.

\section{Objek Penelitian}

Penelitian ini mengambil objek motivasi, kompetensi, dan kinerja Pegawai Negeri Sipil pada Sekretariat Dewan Perwakilan Rakyat Daerah (DPRD) Propinsi Sulawesi Tengah.

\section{Populasi dan Sampel Penelitian}

Populasi yang dipilih sebagai sasaran dalam penelitian ini adalah keseluruhan Pegawai Negeri Sipil Sekretariat Dewan Perwakilan Rakyat Daerah (DPRD) Propinsi Sulawesi Tengah berjumlah 81 orang. Penentuan besarnya sampel dilakukan dengan menggunakan formulasi rumus Slovin yang dikemukakan oleh Taro Yamane (dalam Ridwan, 2005; 65) sebagai berikut :

$$
\mathrm{n}=\frac{\mathrm{N}}{\mathrm{N} \cdot d^{2}+1}
$$

Dimana :

$$
\begin{array}{ll}
\mathrm{n} & =\text { Jumlah sampel } \\
\mathrm{N} & =\text { Jumlah populasi } \\
\mathrm{d}^{2} & =\text { Presisi yang ditetapkan }
\end{array}
$$

Berdasarkan rumus tersebut, dengan besaran presisi sebesar 10\%, maka jumlah sampel sebanyak 45 responden. Dimana teknik penentuan sampel dilakukan dengan metode Purposive Random Sampling, yaitu hanya ditujukan pada Pegawai Negeri Sipil.

\section{Pembahasan}

Regresi Linear Berganda merupakan salah satu alat statistik parametrik dengan fungsi menganalisis dan menerangkan keterkaitan antara dua atau lebih faktor penelitian yang berbeda nama, melalui pengamatan pada beberapa hasil observasi (pengamatan) di berbagai bidang kegiatan. Berkaitan dengan penelitian ini alat analisis Statistik Parametrik Regresi Linear Berganda yang digunakan untuk mengetahui pengaruh variabel independen $(\mathrm{X})$ terhadap variabel dependen (Y). Dalam konteks penelitian ini Regresi Linear Berganda digunakan untuk mengukur pengaruh Motivasi dan Kompetensi terhadap Kinerja Pegawai Negeri Sipil Sekretariat Dewan Perwakilan Rakyat Daerah (DPRD) Propinsi Sulawesi Tengah.

Sesuai hasil analisis Regresi Linear Berganda dengan menggunakan bantuan komputer SPSS diperoleh hasil-hasil penelitian dari 31 orang responden dengan dugaan pengaruh kedua variabel independen (Motivasi dan Kompetensi) terhadap Kinerja Pegawai Negeri Sipil Sekretariat Dewan Perwakilan Rakyat Daerah (DPRD) Propinsi Sulawesi Tengah dapat diketahui hasil perhitungan sebagai berikut : 
Tabel

Hasil Perhitungan Regresi Berganda

\begin{tabular}{|c|c|c|c|}
\hline \multicolumn{4}{|c|}{ Dependen Variabel Y = Kinerja } \\
\hline Variabel & $\begin{array}{c}\text { Undstan } \\
\text { dardized } \\
\text { B }\end{array}$ & $\begin{array}{l}\text { Standar } \\
\text { Error }\end{array}$ & Sig \\
\hline Motivasi & 0.698 & 0.137 & 0.000 \\
\hline Kompetensi & 0.471 & 0.140 & 0.008 \\
\hline \multicolumn{4}{|c|}{ 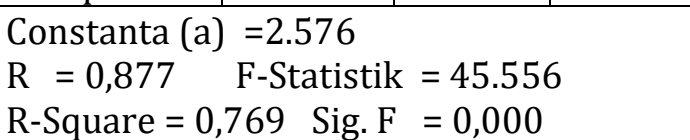 } \\
\hline
\end{tabular}

Sumber: Lampiran

Model regresi yang diperoleh dari tabel di atas adalah :

$$
\mathrm{Y}=\mathbf{2 , 5 7 6}+\mathbf{0 , 6 9 8} \mathrm{X}_{1}+0,471 \mathrm{X}_{2}+\mathrm{e}
$$

Persamaan di atas menunjukkan, variable independen yang dianalisa berupa variabel Motivasi dan Kompetensi memberi pengaruh positip terhadap Kinerja Pegawai Negeri Sipil Sekretariat Dewan Perwakilan Rakyat Daerah (DPRD) Propinsi Sulawesi Tengah dapat dilihat sebagai berikut :

\section{Pengujian Hipotesis Pertama}

Uji serempak adalah sebuah pengujian untuk mengetahui apakah variabel yakni Motivasi dan Kompetensi berpengaruh signifikan terhadap Kinerja Pegawai Negeri Sipil Sekretariat Dewan Perwakilan Rakyat Daerah (DPRD) Propinsi Sulawesi Tengah yakni :

Dari persamaan diatas dapat dijelaskan :

1. Untuk nilai constanta sebesar 2,576 berarti Kinerja Pegawai Negeri Sipil Sekretariat Dewan Perwakilan Rakyat Daerah (DPRD) Propinsi Sulawesi Tengah sebelum adanya variabel independen adalah sebesar 2,576.

2. Untuk nilai dengan koefisien regresi masing-masing sebesar 0,698 untuk Motivasi, dan sebesar 0,471 adalah Kompetensi berarti terjadi hubungan yang positif antara Motivasi dengan
Kinerja Pegawai Negeri Sipil Sekretariat Dewan Perwakilan Rakyat Daerah (DPRD) Propinsi Sulawesi Tengah, demikian pula Kompetensi dengan Kinerja Pegawai Negeri Sipil Sekretariat Dewan Perwakilan Rakyat Daerah (DPRD) Propinsi Sulawesi Tengah terjadi hubungan positif.

Sedangkan dari uji determinasi (kehandalan model) memperlihatkan nilai $\mathrm{R}^{2}=0,769$ atau $=76,9 \%$. Hal ini berarti bahwa sebesar 76,9\% variabel tidak bebas dipengaruhi oleh kedua variabel bebas, selebihnya variabel tidak bebas dipengaruhi oleh variabel lain yang tidak diteliti, misalnya gaji, lingkungan kerja, dan sebagainya.

Selanjutnya berdasarkan tabel dari hasil perhitungan diperoleh $\quad \mathrm{F}_{\text {-hitung }}=$ 45,556 pada taraf nyata $\alpha=0,05$ atau $\mathrm{P}<$ 0,05 . Dari tabel tersebut menunjukkan bahwa nilai signifgikansi Probabilitas $=$ 0,000 . Dengan demikian dapat dinyatakan bahwa secara bersama-sama (serempak) variabel bebas mempunyai pengaruh signifikan terhadap variabel tidak bebasnya.

Dengan demikian maka hipotesis pertama yang menyatakan bahwa : secara serempak Motivasi dan Kompetensi berpengaruh signifikan terhadap Kinerja Pegawai Negeri Sipil Sekretariat Dewan Perwakilan Rakyat Daerah (DPRD) Propinsi Sulawesi Tengah berdasarkan hasil Uji-F ternyata terbukti.

\section{Pengujian Hipotesis Kedua sampai Keempat}

Pengujian secara parsial dimaksudkan untuk melihat pengaruh masing-masing variabel bebas terhadap variabel tidak bebasnya, sebagai berikut :

Motivasi $\left(\mathbf{X}_{1}\right)$

Untuk variabel Motivasi, hasil perhitungannya menunjukkan bahwa nilai 
koefisien regresi sebesar 0,698 , sementara tingkat signifikasi sebesar 0,000 . Dengan demikian nilai $\mathrm{P}<0,05$ pada taraf kepercayaan 95\%. Sehingga dapat dinyatakan bahwa variabel Motivasi mempunyai pengaruh yang signifikan terhadap Kinerja Pegawai Negeri Sipil Sekretariat Dewan Perwakilan Rakyat Daerah (DPRD) Propinsi Sulawesi Tengah.

\section{Kompetensi $\left(\mathbf{X}_{2}\right)$}

Untuk variabel Kompetensi, hasil perhitungannya menunjukkan bahwa nilai koefisien regresi sebesar 0,471, sementara tingkat signifikasi sebesar 0,008 . Dengan demikian nilai $\mathrm{P}<0,05$ pada taraf kepercayaan 95\%. Sehingga dapat dinyatakan bahwa variabel Kompetensi mempunyai pengaruh yang signifikan terhadap Kinerja Pegawai Negeri Sipil Sekretariat Dewan Perwakilan Rakyat Daerah (DPRD) Propinsi Sulawesi Tengah.

Dengan demikian maka hipotesis kedua yang menyatakan bahwa : secara parsial Motivasi berpengaruh signifikan terhadap Kinerja Pegawai Negeri Sipil Sekretariat Dewan Perwakilan Rakyat Daerah (DPRD) Propinsi Sulawesi Tengah, tidak ditolak dan hipotesis ketiga yang menyatakan bahwa : secara parsial Kompetensi berpengaruh signifikan terhadap Kinerja Pegawai Negeri Sipil Sekretariat Dewan Perwakilan Rakyat Daerah (DPRD) Propinsi Sulawesi Tengah, kedua hipotesis tersebut berdasakan uji-t, tidak ditolak.

Sementara untuk hipotesis keempat, dimana dinyatakan bahwa Motivasi memiliki kecenderungan pengaruh yang dominan terhadap Kinerja Pegawai Negeri Sipil Sekretariat Dewan Perwakilan Rakyat Daerah (DPRD) Propinsi Sulawesi Tengah, dilihat dari nilai koefisien regresi (b), maka ditemukan bahwa Motivasi memiliki kecenderungan pengaruh yang dominan dibanding Kompetensi. Dengan demikian maka hipotesis keempat dalam penelitian ini tidak ditolak.

\section{KESIMPULAN}

a. Faktor Motivasi dan Kompetensi secara serempak berpengaruh signifikan terhadap Kinerja Pegawai Negeri Sipil Sekretariat Dewan Perwakilan Rakyat Daerah (DPRD) Propinsi Sulawesi Tengah.

b. Faktor Motivasi berpengaruh signifikan terhadap Kinerja Pegawai Negeri Sipil Sekretariat Dewan Perwakilan Rakyat Daerah (DPRD) Propinsi Sulawesi Tengah.

c. Faktor Kompetensi berpengaruh signifikan terhadap Kinerja Pegawai Negeri Sipil Sekretariat Dewan Perwakilan Rakyat Daerah (DPRD) Propinsi Sulawesi Tengah.

d. Faktor Motivasi berpengaruh dominan terhadap Kinerja Pegawai Negeri Sipil Sekretariat Dewan Perwakilan Rakyat Daerah (DPRD) Propinsi Sulawesi Tengah.

\section{Saran-Saran}

a. Kepada para Pegawai Negeri Sipil Sekretariat Dewan Perwakilan Rakyat Daerah (DPRD) Propinsi Sulawesi Tengah, agar lebih meningkatkan kinerja, dengan berupaya meningkatkan kemampuan diri (kompetensi) sehingga pelayanan yang diberikan menjadi lebih paripurna.

b. Kepada peneliti selanjutnya, agar lebih mengembangkan variabel penelitian dengan menambah variabel lain yang mempengaruhi kinerja aparat pemerintah. 


\section{DAFTAR PUSTAKA}

Amstrong, 1988, Manajemen Sumber Daya Manusia, Erlangga : Jakarta.

Arikunto, 2004, Prosedur Penelitian

Suatu Pendekatan Praktek, Edisi

Revisi, Rineka Cipta : Jakarta.

As'ad Moh, 1981, Psikologi Industri,

Edisi Revisi, Liberty : Yogyakarta.

Bernadin dan Russel, 1993, Human

Relation in Organization, Skill Bull

Aprocoes Irwin USA.

Brittel dan Newstrom, Sjahrudin, 1997,

Pengukuran Kinerja dalam Laporan

Akuntabilitas, Deputy bidang

pengawasan, Unversitas Terbuka

Karumka, Jakarta.

Bya dan Rue, 1981, Human Resource and

Personel Management Skill, Kerperr

Endruo Publiskare, New York.

Cooper dan Emory, 1996, Metode

Penelitian Bisnis, Jilid I, Edisi

kelima, Erlangga : Jakarta.

Dessler, Gary, 1997, Human Resource

Management, terjemahan, Jilid 2,

Prehandilindo : Jakarta.

Fllipo, Edmin B, 1990, Personel Management, Edisi keenam,

Terjemahan, Erlangga : Jakarta.

Gitosudarmo, 2000, Sumber Daya Manusia, Edisi kedua, Bina Askara : Jakarta.

Gomes, Faustino, C, 1999, Manajemen Sumber Daya Manusia, Cetakan Pertama, Andi Offset : Yogyakarta.

Handoko, T.Hani, 1989, Manajemen Personalia dan Sumber Daya Manusia, Edisi kedua, BPFE : Yogyakarta.

Hasibuan, Malayu, S. P., 2008, Manajemen Sumber Daya Manusia, cetakan kesebelas, diterbitkan oleh PT. Bumi Aksara : Jakarta.
Harahap, Paramean, 1992, Manajemen Sumber Daya Manusia, Edisi kedua, BPFE : Yogyakarta.

Hardianto, 2004, Pembinaan Karier Pegawai Negeri Sipil Negeri Sipil, Warta Ke Pegawai Negeri Sipil, Badan Ke Pegawai Negeri Sipil Negara $(\mathrm{BKN})$ : Jakarta.

Hasan, M.I, 2002, Metereologi Penelitian dan Aplikasinya, Ghalia Indonesia : Jakarta.

Indrawijaya, 1989, Perilaku Organisasi, Cetakan ketiga, Sinar : Bandung.

Kaiyeli, N. (2021). Pengaruh Kompensasi, Pengalaman Kerja Dan Komitmen Organisasi Terhadap Kinerja Pegawai Negeri Sipil (Pns) Pada Dinas Pekerjaan Umum Daerah Kabupaten Sigi. Jurnal Ekonomi Trend, 7(1), 41-57. Https://Doi.Org/10.31970/Trend.V7 i1.172

Karyawan Noe, 1994, Human Resource management, Irwin USA.

Lussler, 1996, Human Relation in Organization, skill build Approach, Irwin USA.

Malholtra, 1993, Metode Penelitian, PT. Grafika Indo : Jakarta.

Marjun, M. (2019). Pengaruh Di Mensi Dimensi Kualitas Layanan Terhadap Kepuasan Pasien Rawat Inap Bpjs Kesehatan Center Rumah Sakit Umum Daerah Anutapura. Jurnal Ekonomi Trend, 7(1), 12-26. Https://Doi.Org/10.31970/Trend.V7 i1.170

Mc. Ashan, Peni, 2004, Model Pelatihan Penilik PLS Berbasis Kompetensi, Balai Pengembangan Pendidikan Luar Sekolah dan Pemuda Regional III : Ungaran. 
Mudrajad, Kuncoro, 2001, Otonomi Pembangunan Daerah, Erlangga : Jakarta.

Mulyasa, 2002, Kurikulum Berbasis Kompetensi, Cetakan pertama, PT. Remaja Ros dakarya : Bandung.

Noe, 1994, Human Resource management, Irwin. USA.

Prasetyo, B, Janna, L.M, 2008, Metode Penelitian Kuantitatif, PT. Raja Grafindo Persada : Jakarta.

Prawiro, Sentono, 1999, Manajemen Sumber Daya Manusia, Kebijakan Kinerja Karyawan Kiat Membangun Organisasi Kompetitif Menjelang Perdagangan Bebas Dunia, edisi pertama, cetakan pertama, BPFE : Yogyakarta.

Prihadi, 2004, Asessment Center Identifikasi, Pengukuran dan Pengembangan Kompetensi, cetakan kedua, PT. Gramedia Pustaka Utama.

Raharso, 2004, Competence Based Organisation, Penyelenggara antara Kompetensi Individu Dengan Core Competence Organisasi. Manajemen Usahawan Indonesia, No 10/Tahun XXXIII

Rahman, A. (2019). Pengaruh Hubungan Interpersonal, Lingkungan Kerja, Dan Kecerdasan Emosional Terhadap Kinerja Pegawai Pada Kantor Komisi Pemilihan Umum Daerah (Kpud) Kabupaten Parigi Moutong. Jurnal Ekonomi Trend, 7(1), 58-70. Https://Doi.Org/10.31970/Trend.V7 i1.173

Rangkuti, 1997, Analisis Swot Teknik Membedah Kasus Bisnis, PT. Gramedia Pustaka Utama : Jakarta.
Riduwan, 2008, Metode dan Teknis Menyusun Tesis, Alfabeta : Bandung.

Riduwan, dan Sunarto, H. 2007. Pengantar Statistika Untuk Penelitian Pendidikan, Sosial, Ekonomi, Motivasi dan Bisnis, Alfabeta : Bandung.

Robbins, Stephen P, 1996, Perilaku Organisasi Konsep Kontraversi, dan Aplikasi terjemahan, PT. Prenhalindo : Jakarta.

Sarwono. J, 2008. Panduan Cepat dan Mudah SPSS 14. Penerbit Andi : Yogyakarta.

Siegel, Sydney, 1997, Statistik Non Parametrik Untuk Ilmu-Ilmu Sosial, penerbit PT. Gramedia Pustaka Utama.

Sjahrudin, Azwar, 1997, Reliabilitas dan Validitas, Edisi ketiga, Pustaka Pelajar.

Soeprihanto, 2000, Penilaian Kinerja dan Pengembangan Karyawan, Edisi Pertama, BPFE : Yogyakarta.

Spencer, 1993, Competence Of Work, New York. Jhon Wiley \& Sons, Inc.

Sudrajat, 2002, Metode Penelitian,PT. Grafika Indo : Jakarta.

Sulipan, 2005, Pendidikan dan Pelatihan Berbasis Kompetensi (Competency Based training), TEDC : Bandung.

Sugiono, 1999, Metode Penelitian Administrasi, Penerbit Alfabeta : Bandung.

-------, 2008, Metode Penelitian Bisnis, Cetakan kesebelas Januari 2008.

Walpole, Ronald, 1992, Pengantar Statistik, Penerbit PT.Gramedia Pustaka Utama : Jakarta.

Winardi, 2001 Motivasi dan Pemotivasian dalam Manajemen. PT. Raja Grafindo Persada : Jakarta. 